\title{
Papers
}

\section{Monoamine oxidase type B inhibitors in early Parkinson's disease: meta-analysis of 17 randomised trials involving 3525 patients}

Natalie J Ives, Rebecca L Stowe, Joanna Marro, Carl Counsell, Angus Macleod, Carl E Clarke, Richard Gray, Keith Wheatley

\begin{abstract}
Objective To quantify more reliably the benefits and risks of monoamine oxidase type B inhibitors (MAOBIs) in early Parkinson's disease.

Data sources Searches of the Cochrane Library, Medline, Embase, PubMed, and Web of Science for years 1966-2003, plus major journals in the field, abstract books, and proceedings of meetings, for randomised trials comparing MAOBIs with placebo or levodopa.

Data extraction Available data on mortality, motor complications, side effects, treatment compliance, and clinician rated disability (for example, unified Parkinson's disease rating scale) were extracted from 17 trials and combined using standard meta-analytic methods.

Results No significant difference in mortality existed between patients on MAOBIs and control patients (odds ratio 1.13, 95\% confidence interval 0.94 to $1.34 ; \mathrm{P}=0.2$ ). Patients randomised to MAOBIs had significantly better total scores, motor scores, and activities of daily living scores on the unified Parkinson's disease rating scale at three months compared with patients taking placebo; they were also less likely to need additional levodopa $(0.57,0.48$ to $0.67 ; \mathrm{P}<0.00001)$ or to develop motor fluctuations $(0.75,0.59$ to $0.95 ; \mathrm{P}=0.02)$. No difference existed between the two groups in the incidence of side effects or withdrawal of patients.

Conclusions MAOBIs reduce disability, the need for levodopa, and the incidence of motor fluctuations, without substantial side effects or increased mortality. However, because few trials have compared MAOBIs with other antiparkinsonian drugs, uncertainty remains about the relative benefits and risks of MAOBIs. Further large, long term comparative trials that include patient rated quality of life measures are needed.
\end{abstract}

\section{Introduction}

Clinical decline in Parkinson's disease results from degeneration of nigrostriatal dopaminergic neurones. This process may be mediated by oxidative free radicals, which in animal models of Parkinson's disease can be inhibited by monoamine oxidase type B inhibitors (MAOBIs), such as selegiline. ${ }^{1}$ Consequently, selegiline has been used either alone or in addition to levodopa in both early and later Parkinson's disease in the hope that it may slow disease progression. Clinical trials in the 1980 s, such as the DATATOP study, ${ }^{2}$ suggested that selegiline might have a neuroprotective effect, but this remains controversial. ${ }^{3}$ Further uncertainty about MAOBIs arose in 1995, when a study by the Parkinson's Disease Research Group of the United Kingdom
(UK-PDRG) closed its selegiline arm after finding 57\% higher mortality in patients receiving combined selegiline and levodopa treatment compared with patients on levodopa alone. ${ }^{4}$ Other randomised trials have, however, failed to show any increase in mortality. ${ }^{56}$

To clarify the role of MAOBIs, we did a meta-analysis of data from all published trials comparing any MAOBI with either levodopa or placebo in early Parkinson's disease. Meta-analyses give a more accurate view of the randomised evidence, because they include more patients than does any single trial, so random errors are smaller. Also, by reviewing data from all relevant trials, a more balanced assessment is obtained.

\section{Methods}

\section{Identification of trials}

We systematically searched the literature from 1966 to December 2003 to identify randomised trials of MAOBIs in early Parkinson's disease, using the search strategy recommended by the Cochrane Collaboration. ${ }^{7}$ This involved searching electronic databases including the Cochrane Library, Medline, Embase, PubMed, and Web of Science and hand searching major journals in the field, abstract books, conference proceedings, and reference lists of retrieved publications.

\section{Inclusion criteria}

Eligible studies had to be randomised trials in early Parkinson's disease comparing an MAOBI (selegiline, lazabemide, or rasagiline), with or without levodopa, versus placebo, levodopa, or both, with all other aspects of treatment being the same in both arms. We defined early disease as patients with idiopathic Parkinson's disease who had no history of motor complications and were untreated or had received limited (generally less than 12 months) exposure to antiparkinsonian drugs.

\section{Outcome measures}

Two independent reviewers extracted outcome data, which were validated by a third reviewer, with any discrepancies resolved by consensus. Data extracted included mortality; clinician rated disability scales, such as the unified Parkinson's disease rating scale; need for levodopa; incidence of motor complications; side effects; and withdrawal of patients from the trial. We used outcome data at the longest available follow up, other than for unified Parkinson's disease rating scale data, which we analysed at three months after randomisation (except for two studies, for 
which we used data at one month and six weeks). Although published scores only give a crude idea of quality, two investigators independently scored the methodological quality of the included studies.

\section{Statistical analysis}

We combined results of each trial by using standard meta-analytic methods to estimate an overall treatment effect for MAOBI versus non-MAOBI treated patients. We subclassified trials according to the randomised treatment comparison: MAOBI versus placebo; MAOBI+levodopa (LD) versus placebo+LD or MAOBI+LD versus $\mathrm{LD}$ (classified as MAOBI+LD versus $\mathrm{LD}$ ); and MAOBI versus $\mathrm{LD}$. We used tests of heterogeneity to assess for differences in treatment effects between trials and subgroups of trials. ${ }^{.}$

For event data (such as mortality) we obtained estimates of the treatment effects for most trials from the number of events reported in each arm and used the methods of Mantel and Haenszel to combine them. ${ }^{9}{ }^{10}$ This involved comparing the number of events observed with the number of events that would have been expected if the probability of that event was unrelated to treatment. For each trial we calculated the "observed minus expected" difference and its variance. Summing these statistics for each trial provided the overall statistics that we used to calculate odds ratios with 95\% confidence intervals. ${ }^{811}$ However, if a hazard ratio, odds ratio, relative risk, or odds reduction, plus a confidence interval or a $\mathrm{P}$ value, was available then we used this information to obtain a more accurate estimate of the treatment effect. $^{12}$

For continuous variables (such as clinician rated disability scales), we used weighted mean difference methods. ${ }^{13}$ For each trial we calculated the difference (and its variance) between the means of the outcome measure for each treatment group. We combined these values to give the overall weighted mean difference and its standard error, with $95 \%$ confidence interval, for this pooled estimate of the mean difference.

\section{Results}

\section{Trials and patients}

We identified 18 randomised trials of MAOBI treatment in early Parkinson's disease. (See fig A on bmj.com for QUORUM statement flow diagram.) We excluded one crossover study, as the trial did not provide data split by treatment period. ${ }^{14}$ We therefore included 17 trials involving 3525 patients in this meta-analysis (table 1 and table on bmj.com). ${ }^{45-36}$ Thirteen trials were of selegiline, three were of lazabemide, and one was of rasagiline. Duration of treatment varied from six weeks to 10 years; shorter trials assessed symptomatic control and tolerability, and longer trials assessed disease progression and mortality. One trial contributed data to more than one comparison (MAOBI $v$ placebo and MAOBI+LD $v$ LD).$^{24}$ In the UK-PDRG study, patients who had inadequate symptom control or were unable to tolerate their original allocation to the dopamine agonist bromocriptine were re-randomised to selegiline plus levodopa or levodopa alone. ${ }^{4}$

Table 2 shows the methodological quality of the included trials. Ten trials described the method of randomisation used (blocking, random number generator, computer); only four trials clearly had an adequate concealment of allocation procedure (by virtue of a central randomisation service). All trials provided information on blinding (15/17 trials were double blind), and all trials reported follow up data, although some trials did not include all randomised patients in the final analyses despite claiming to have used an intention to treat analysis.

\section{Mortality}

Mortality data were available from nine trials of selegiline and one of lazabemide (fig 1). We considered the UK-PDRG study, which initially reported $76 / 271(28 \%)$ deaths in the selegiline arm compared with 44/249 (18\%) deaths in the levodopa arm (odds ratio $1.57,95 \%$ confidence interval 1.09 to $2.30 ; \mathrm{P}=0.015$ ) to be hypothesis generating. ${ }^{4}$ In the other trials, which we treated as confirmatory studies, no excess of deaths occurred with MAOBI compared with the control arm (15.5\% v 18.2\% deaths; odds ratio $1.02,0.84$ to $1.25 ; \mathrm{P}=0.8$ ). Taking all available data, $287(20 \%)$ deaths occurred in 1436 MAOBI patients compared with $257(21 \%)$ in 1215 control patients (odds ratio 1.13, 0.94 to $1.34 ; \mathrm{P}=0.2)$. We found no significant heterogeneity between trials $(\mathrm{P}=0.6)$, even including the UK-PDRG study.

\section{Clinical disability rating scales}

Data from rating scales were available from only six trials of selegiline. ${ }^{15} 1924262732$ Unified Parkinson's disease rating scale scores at three months were 2.7 (95\% confidence interval 1.4 to 4.1 ; $\mathrm{P}=0.00009), 1.8$ (0.8 to $2.7 ; \mathrm{P}=0.0004)$, and 0.9 (0.5 to 1.4 ; $\mathrm{P}=0.00007)$ points better with selegiline than with control for total score, motor score, and activities of daily living score (see figs B-D on bmj.com). The large DATATOP study accounted for more than $65 \%$ of the patients analysed and more than $79 \%$ of patients in the MAOBI versus placebo comparison. ${ }^{32}$ However, combined results from the other two studies of MAOBI versus placebo were consistent with those from DATATOP and independently significant $(\mathrm{P}=0.004) .{ }^{15} 19$

\section{Need for levodopa}

For the 12 trials comparing an MAOBI with placebo, data on the need for levodopa were available from eight studies with a median follow up of 13 months (range 3 months to 5 years). ${ }^{19-23} 263133$ A highly significant reduction in the need for levodopa occurred in patients randomised to an MAOBI compared with those on placebo (odds ratio $0.57,0.48$ to 0.67 ; $\mathrm{P}<0.00001$; fig 2). For trials comparing selegiline and levodopa with levodopa alone, adequate data on dose of levodopa for meta-analysis were available from two trials. ${ }^{24}{ }^{27}$ The dose of levodopa needed for adequate symptom control was 67 (14 to 119; $\mathrm{P}=0.01) \mathrm{mg}$ lower in the selegiline arm.

\section{Motor complications}

Data on motor complications were available from five trials. ${ }^{25} 27283035$ A $25 \%$ reduction in motor fluctuations occurred in patients randomised to an MAOBI (odds ratio $0.75,0.59$ to 0.95 ; $\mathrm{P}=0.02$; fig 3). However, we found no difference in the incidence of dyskinesia between the MAOBI and non-MAOBI groups (odds ratio $0.97,0.75$ to $1.26 ; \mathrm{P}=0.8$; fig 3 ). We found no evidence of heterogeneity between the trials or the three treatment comparisons for either outcome.

\section{Side effects and withdrawals}

More side effects were reported in patients randomised to an MAOBI, which was of borderline significance (odds ratio 1.36, 1.02 to $1.80 ; \mathrm{P}=0.04)$. Data on specific side effects were rarely reported, so any subanalysis of these data is of limited value. More MAOBI patients than non-MAOBI patients withdrew owing to adverse events (odds ratio 2.16, 1.44 to $3.23 ; \mathrm{P}=0.0002$; fig 4), with some evidence of heterogeneity between trials $(\mathrm{P}=0.03)$ but not between the three treatment comparisons $(\mathrm{P}=0.09)$. This heterogeneity was explained by the atypical results in the UK-PDRG study, which reported significantly more dropouts due to adverse events in the open label selegiline plus levodopa arm than with levodopa alone (14\% v 3\%). In contrast, significantly more patients were withdrawn from this trial in the 
Table 1 Characteristics of trials of monoamine oxidase type B inhibitors included in meta-analysis

\begin{tabular}{|c|c|c|c|c|}
\hline Trial & Comparison* & No. randomised (MAOBI/control) & $\begin{array}{l}\text { Treatment period (length of follow } \\
\text { upt) }\end{array}$ & Outcome data reported $\ddagger$ \\
\hline \multicolumn{5}{|c|}{ Short term tolerability trials } \\
\hline Hungary-Scotland ${ }^{15}$ & Selegiline $v$ placebo & $20(10 / 10)$ & 6 weeks & Disability, dropouts \\
\hline PSG lazabemide $1^{16}$ & Lazabemide $v$ placebo & $201(150 / 51)$ & $\begin{array}{l}4 \text { or } 6 \text { weeks then washout ( } 8 \\
\text { weeks) }\end{array}$ & $\begin{array}{l}\text { Tolerability, disability, side effects, } \\
\text { dropouts }\end{array}$ \\
\hline PSG lazabemide $2^{17}$ & Lazabemide+LD $v$ placebo+LD & $137(105 / 32)$ & $\begin{array}{l}4 \text { or } 6 \text { weeks then washout ( } 8 \\
\text { weeks) }\end{array}$ & $\begin{array}{l}\text { Tolerability, disability, side effects, } \\
\text { dropouts }\end{array}$ \\
\hline Italy-Germany ${ }^{18}$ & Selegiline+lisuride $v$ placebo+lisuride & $20(10 / 10)$ & 3 months & Disability, lisuride dose, dropouts \\
\hline \multicolumn{5}{|c|}{ Longer term efficacy trials } \\
\hline France $^{19}$ & Selegiline $v$ placebo & $93(48 / 45)$ & 3 months & $\begin{array}{l}\text { Disability, need for LD, side effects, } \\
\text { dropouts }\end{array}$ \\
\hline PSG TEMPO ${ }^{20}$ & Rasagiline $v$ placebo & $404(266 / 138)$ & 6 months & $\begin{array}{l}\text { Disability, need for LD, side effects, } \\
\text { dropouts }\end{array}$ \\
\hline Swedish PSG ${ }^{21}$ & Selegiline $( \pm \mathrm{LD}) v$ placebo $( \pm \mathrm{LD})$ & $157(81 / 76)$ & $\begin{array}{l}12 \text { months } \dagger \text { (need for LD at } 60 \\
\text { months) }\end{array}$ & $\begin{array}{l}\text { Need for LD, disability, mortality, } \\
\text { dropouts }\end{array}$ \\
\hline UK Middlesex ${ }^{22}$ & Selegiline $v$ placebo & $30(14 / 16)$ & 54 weeks or until LD & $\begin{array}{l}\text { Disability, need for LD, mortality, } \\
\text { side effects, dropouts }\end{array}$ \\
\hline PSG lazabemide $3^{23}$ & Lazabemide $v$ placebo & $321(255 / 66)$ & $\begin{array}{l}52 \text { or } 54 \text { weeks or until LD, then } \\
\text { washout }\end{array}$ & $\begin{array}{l}\text { Need for LD, disability, side effects, } \\
\text { dropouts }\end{array}$ \\
\hline USA (bromocriptine) ${ }^{24}$ & $\begin{array}{l}\text { Selegiline+bromocriptine } v \\
\text { placebo+bromocriptine }\end{array}$ & $52(27 / 25)$ & 14 months & $\begin{array}{l}\text { Disability, mortality, LD dose, } \\
\text { dropouts }\end{array}$ \\
\hline USA (levodopa) ${ }^{24}$ & Selegiline+LD $v$ placebo+LD & $49(25 / 24)$ & 14 months & $\begin{array}{l}\text { Disability, mortality, LD dose, } \\
\text { dropouts }\end{array}$ \\
\hline Italy ${ }^{25}$ & Selegiline $( \pm \mathrm{LD}) v \mathrm{LD}$ & $332(166 / 166)$ & Median=34 months $\dagger$ & $\begin{array}{l}\text { Motor complications, mortality, } \\
\text { dropouts }\end{array}$ \\
\hline California $^{26}$ & Selegiline $v$ placebo & $54(27 / 27)$ & 3 years or until LD, then washout & $\begin{array}{l}\text { Need for LD, disability, side effects, } \\
\text { dropouts }\end{array}$ \\
\hline Norway-Denmark ${ }^{27}$ & Selegiline+LD $v$ placebo+LD & $163(77 / 86)$ & 5 years & $\begin{array}{l}\text { Disability, motor complications, } \\
\text { mortality, LD dose, side effects, } \\
\text { dropouts }\end{array}$ \\
\hline SELED $0^{28}$ & Selegiline+LD $v$ placebo+LD & $116(61 / 55)$ & 5 years & $\begin{array}{l}\text { Time to } 50 \% \text { increase in LD dose, } \\
\text { disability, mortality, motor } \\
\text { complications, side effects, dropouts }\end{array}$ \\
\hline Finland $^{29-31}$ & Selegiline $( \pm \mathrm{LD}) v$ placebo $( \pm \mathrm{LD})$ & 56 (52 analysed) (28/28) & $\begin{array}{l}\text { Approximately } 6 \text { years } † \text { (need for LD } \\
\text { at } 4 \text { years) }\end{array}$ & $\begin{array}{l}\text { Need for LD, LD dose, disability, } \\
\text { motor complications, mortality, } \\
\text { dropouts }\end{array}$ \\
\hline DATATOP $32-34$ & $\begin{array}{l}\text { Selegiline } v \text { placebo (until LD } \\
\text { needed)§ ( } \pm \text { tocopherol in each arm) }\end{array}$ & $800(399 / 401)$ & $\begin{array}{l}\text { Mean }=8.2 \text { yearst (need for LD and } \\
\text { dropouts at mean } 14 \text { months) }\end{array}$ & $\begin{array}{l}\text { Need for LD, disability, mortality, } \\
\text { dropouts }\end{array}$ \\
\hline UK-PDRG ${ }^{43} 36$ & $\begin{array}{l}\text { Selegiline + LD } v \text { LD (until selegiline } \\
\text { arm closed) }\end{array}$ & $520(271 / 249)$ & $\begin{array}{l}10 \text { years (dropouts at approximately } \\
6 \text { years) }\end{array}$ & $\begin{array}{l}\text { Mortality, disability, LD dose, motor } \\
\text { complications, dropouts }\end{array}$ \\
\hline
\end{tabular}

$\mathrm{LD}=$ =levodopa; $\mathrm{MAOBI}=$ monoamine oxidase type $\mathrm{B}$ inhibitor.

${ }^{*} \pm \mathrm{LD}$ indicates that trial design allowed levodopa to be added to the randomised treatment.

tIn all cases the length of follow up equalled the planned treatment period, except for the Swedish PSG study in which 7 years' treatment was planned. In the Finland study, patients were on monotherapy (selegiline $v$ placebo) for approximately 1.2 years then followed for 5 years on combination treatment. For the Italy and DATATOP studies, median and mean lengths of follow up were stated.

‡Not all outcome data reported were available for meta-analysis. Disability refers to clinician rated disability scales (such as unified Parkinson's disease rating scale, Hoehn and Yahr, Webster).

$\S$ Study closed early and 310 patients who had not reached endpoint were treated with open label selegiline.

levodopa arm owing to protocol violations (1\% v 15\%); 28/37 patients were withdrawn following the introduction of selegiline to their treatment regimen after publication of the DATATOP trial results. An analysis of the data on dropouts due to adverse events for placebo controlled trials only (that is, excluding the UK-PDRG and Italy studies) showed no difference between MAOBI and non-MAOBI patients (odds ratio 1.52, 0.87 to 2.68; $\mathrm{P}=0.1$ ), with no evidence of heterogeneity between trials $(\mathrm{P}=0.2)$ or between the two treatment comparisons $(\mathrm{P}=0.9)$.

We found no difference between the two groups (MAOBI $v$ non-MAOBI) in the overall numbers of patients withdrawing from the trials $(18 \% v 19 \%$; odds ratio $1.06,0.87$ to $1.28 ; \mathrm{P}=0.6)$. However, patients withdrew from different trials for quite varied reasons-such as lack of efficacy, toxicity, patients given selegiline by their general practitioners after publication of the DATATOP study - and this is reflected in the significant heterogeneity between trials $(\mathrm{P}=0.007)$, making it difficult to interpret overall withdrawal rates.

\section{Discussion}

This is the first systematic review to assess MAOBIs as a drug class in early Parkinson's disease and the most comprehensive in the range of outcomes assessed. It provides the most reliable available summary of the current evidence from clinical trials of MAOBIs in the treatment of early Parkinson's disease and clarifies previous uncertainties about the role of these drugs.

One fundamental objective was to investigate whether MAOBIs, and selegiline in particular, increase mortality in patients with Parkinson's disease, as suggested by the UK-PDRG trial. ${ }^{4}$ Our systematic review provides evidence to refute this hypothesis; no increase in mortality was seen in the other trials, either individually or in the pooled data, or in subsequent follow up of the UK-PDRG trial. ${ }^{35}$ It therefore seems likely that the early excess of deaths in the selegiline arm of the UK-PDRG study compared with the levodopa arm was a chance finding, although the confidence interval reported in this review is compatible with a small increase, or indeed decrease, in mortality.

Our systematic review also shows that early use of selegiline delays the need for levodopa and that when selegiline is given 


\begin{tabular}{|c|c|c|c|c|}
\hline Trial & Randomisation* & Concealment of allocation $†$ & Blindingł & Follow up§ \\
\hline \multicolumn{5}{|c|}{ Short term tolerability trials } \\
\hline Hungary-Scotland ${ }^{15}$ & 1 & 0 & 1 & 2 \\
\hline PSG lazabemide $1^{16}$ & 1 & 0 & 1 & 2 \\
\hline PSG lazabemide $2^{17}$ & 1 & 0 & 1 & 2 \\
\hline Italy-Germany ${ }^{18}$ & 1 & 0 & 1 & 2 \\
\hline \multicolumn{5}{|c|}{ Long term efficacy trials } \\
\hline France $^{19}$ & 2 & 0 & 1 & 1 \\
\hline PSG TEMPO ${ }^{20}$ & 1 & 0 & 1 & 2 \\
\hline Swedish PSG ${ }^{21}$ & 1 & 0 & 1 & 1 \\
\hline UK Middlesex ${ }^{22}$ & 1 & 0 & 1 & 1 \\
\hline PSG lazabemide $3^{23}$ & 2 & 0 & 1 & 2 \\
\hline $\mathrm{USA}^{24}$ & 2 & 0 & 1 & 1 \\
\hline Italy $y^{25}$ & 2 & 1 & 0 & 1 \\
\hline California $^{26}$ & 2 & 0 & 1 & 1 \\
\hline Norway-Denmark ${ }^{27}$ & 2 & 1 & 1 & 1 \\
\hline SELEDO $^{28}$ & 2 & 0 & 1 & 1 \\
\hline Finland $^{29-31}$ & 2 & 0 & 1 & 1 \\
\hline DATATOP ${ }^{22-34}$ & 2 & 1 & 1 & 2 \\
\hline UK-PDRG ${ }^{4} 3536$ & 2 & 1 & 0 & 2 \\
\hline
\end{tabular}

${ }^{*} 0=$ none; $1=y e s$, method used not given; $2=y e s$, method used given (blocking, random numbers, computer generated lists)

† $0=$ none, not stated, or not clear; $1=y e s$.

$\ddagger 0=$ no; $1=$ yes (double blind).

$\S 0=$ none reported; $1=$ reported, data not analysed according to intention to treat; $2=$ reported, data analysed according to intention to treat

concomitantly with levodopa lower doses of levodopa are needed. This may be due to symptomatic relief from selegiline: total scores, motor scores, and activities of daily living scores on the unified Parkinson's disease rating scale were significantly better with selegiline than with placebo in the first three months of treatment. (The lack of apparent benefit from selegiline when added to levodopa or bromocriptine is probably explained by adjustments in the dose of the concomitant drug.) However, whether the benefits seen are large enough to be clinically important is debatable. Avoiding exposure to levodopa should reduce the risk of developing motor complications, which are believed to be a consequence of long term use of levodopa. In the few studies that reported these data, fewer selegiline patients developed motor fluctuations. Interestingly, no reduction in dyskinesia was observed, although a benefit cannot be excluded given the wide confidence intervals. The reduction in motor fluc-

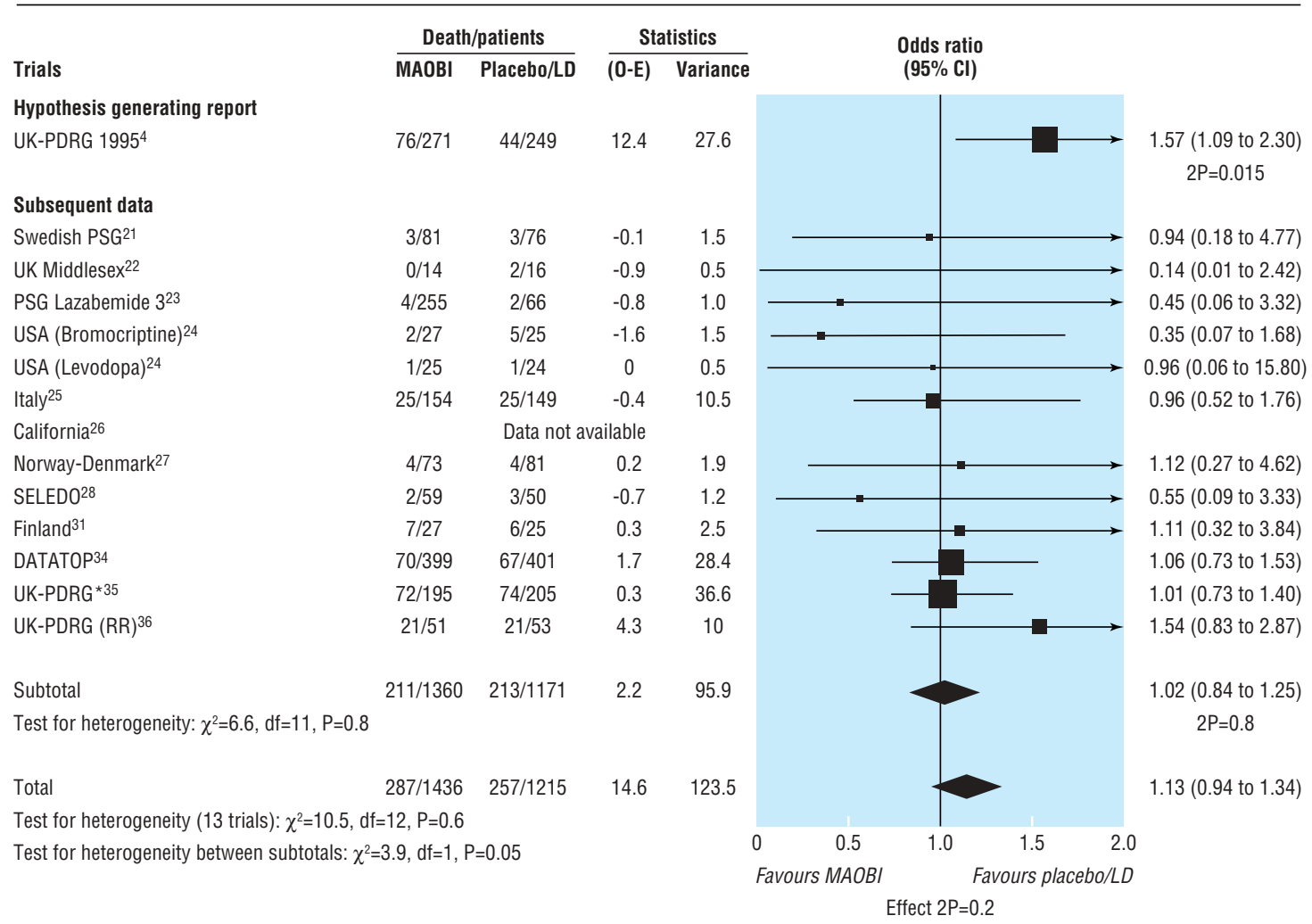

Fig 1 Mortality in trials of monoamine oxidase type B inhibitors. ( $L D=l e v o d o p a ; M A O B I=$ monoamine oxidase type B inhibitor; 0 - $E=0$ observed minus expected; $R R=$ re-randomisation data from UK-PDRG. *Data from subsequent follow up of UK-PDRG trial一patients counted only once in total denominator) 


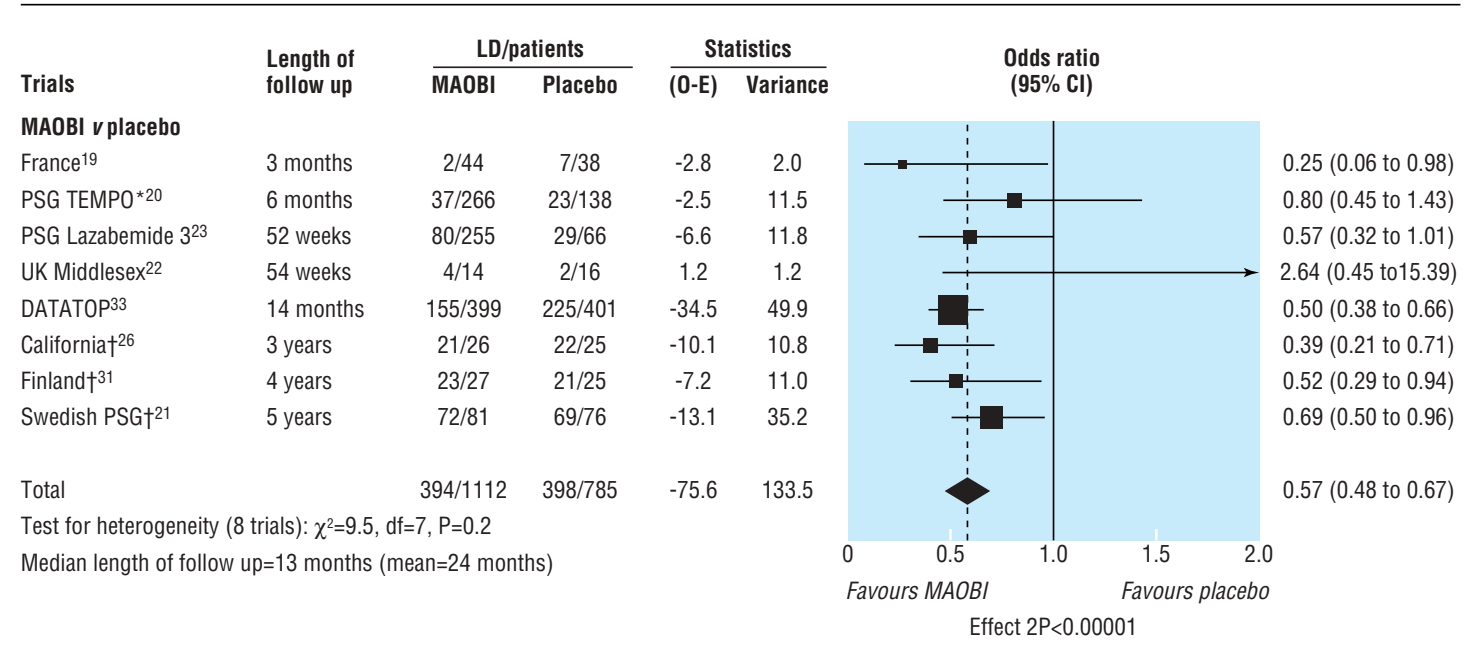

Fig 2 Need for levodopa treatment in trials comparing monoamine oxidase type B inhibitors and placebo. ( 0 -E=observed minus expected; LD=levodopa; $\mathrm{MAOBI}=$ monoamine oxidase type $\mathrm{B}$ inhibitor. ${ }^{*}$ Rasagiline. $† 0-E$ and variance based on published time to event analyses)

tuations could be due to lower exposure to levodopa or to a neuroprotective effect of selegiline. A reduction in motor complications has also been observed with dopamine agonists, the other levodopa sparing agents commonly used in early Parkinson's disease, ${ }^{37}$ and similar uncertainties exist about the mechanisms underlying this observation.

Our review provides no evidence that mortality is increased by selegiline and suggests that this inexpensive drug could be one of the most clinically effective and cost effective treatments available for early Parkinson's disease. However, despite promising clinical trial results, use of selegiline in the United Kingdom dropped substantially after the UK-PDRG report of increased mortality. ${ }^{4}$ Data on the other MAOBIs, lazabemide and rasagiline, are consistent with those seen with selegiline, but the limited information available makes any conclusions on the role of MAOBIs as a class difficult.

The review also highlights the lack of data on the long term balance of benefits and risks of MAOBIs. A lack of trials that directly compare active treatments (for example, MAOBI versus dopamine agonists), as well as poor reporting of results in many trials, short term follow up, and a lack of patient rated quality of life data, limits the interpretation and applicability of these results. To determine more reliably the role of MAOBIs in early Parkinson's disease, further large, well designed randomised trials that evaluate the long term balance of benefit and harm, comparing MAOBIs with other active agents, such as dopamine agonists and levodopa, are urgently needed-for example, the PD MED trial (www.pdmed.bham.ac.uk (accessed 22 Jun 2004)). This can be achieved by using patient rated quality of life scales, such as the Parkinson's disease questionnaire (PDQ-39), which assess all aspects of the patient's life and are sensitive to changes that are meaningful to patients, as the main outcome measure. ${ }^{38}$

We recognise the work of all the original trial teams and the people who did the trials that contributed to this meta-analysis, and we thank the patients who agreed to help future patients by taking part in these trials.

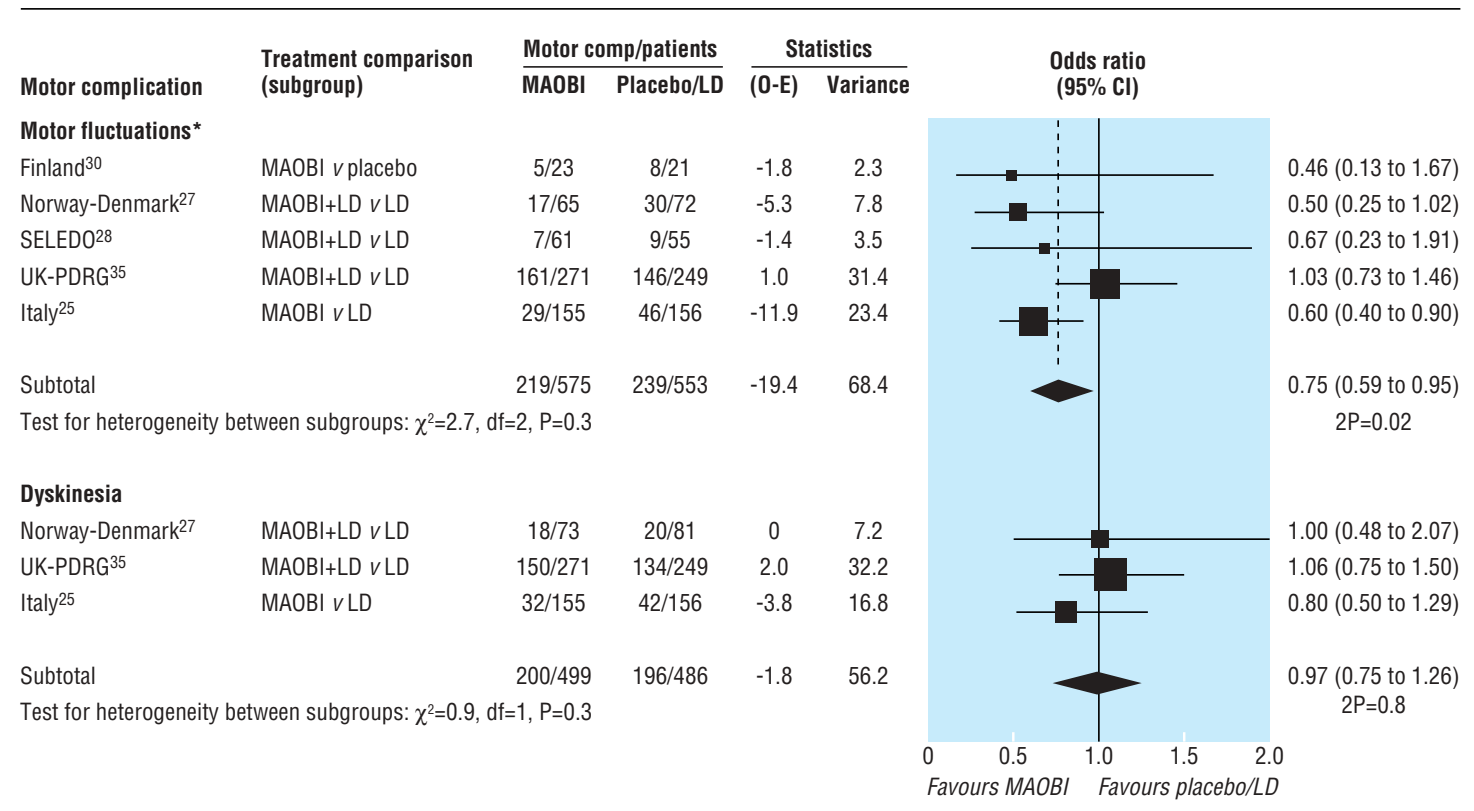

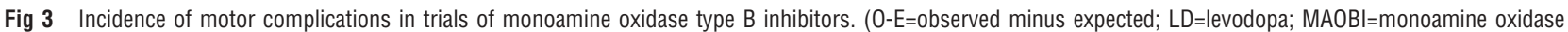
type $B$ inhibitor. *Motor fluctuations defined as on-off or end of dose fluctuations, wearing off, or random oscillations) 


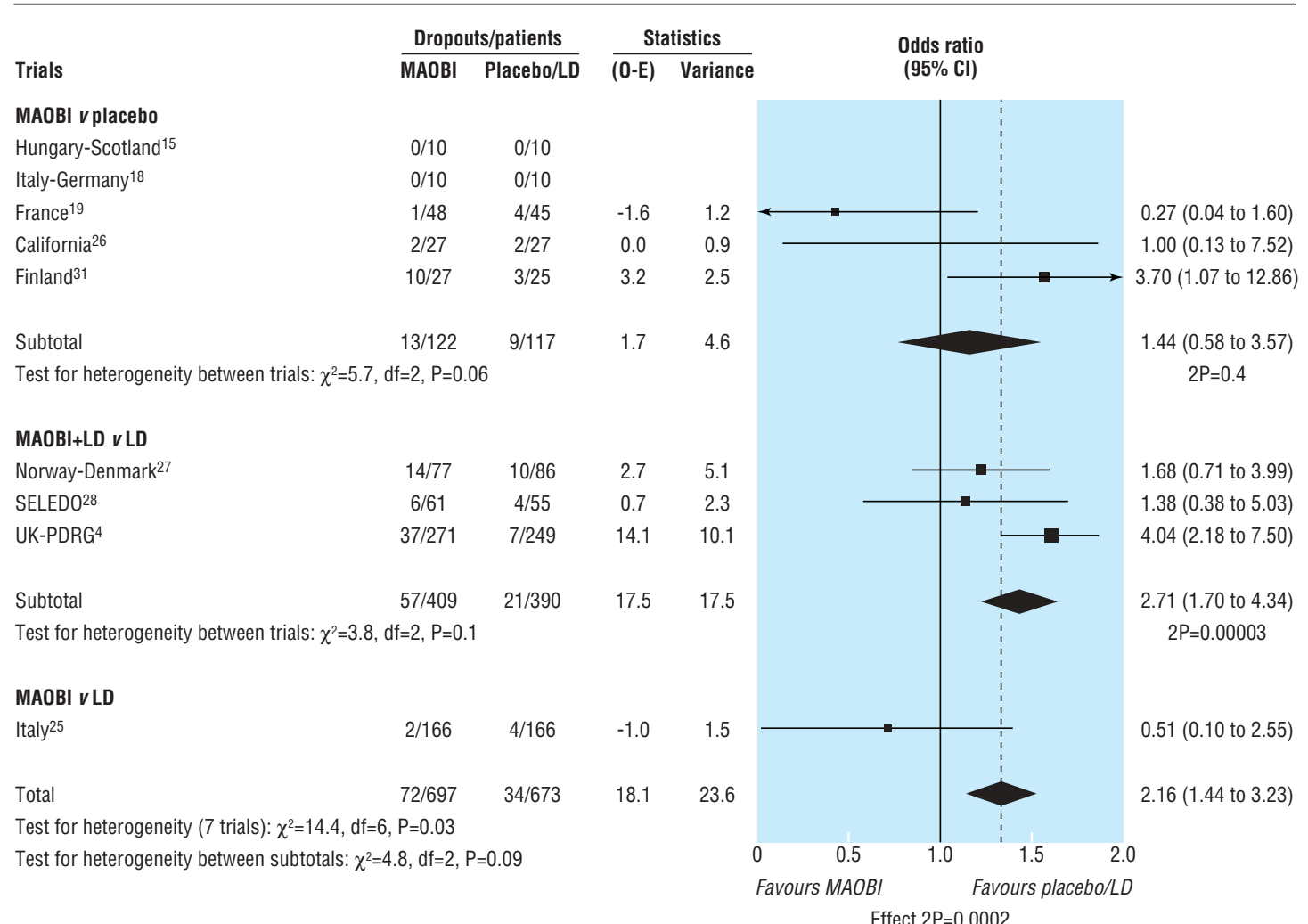

Fig 4 Withdrawal of patients due to adverse events in trials of monoamine oxidase type B inhibitors ( $0-E=0 b s e r v e d$ minus expected; $L D=l e v o d o p a ;$ $\mathrm{MAOBI}=$ monoamine oxidase type B inhibitor)

Contributors: All authors contributed to the design, analysis, and interpretation of the study. NI is the guarantor.

Funding: This work was funded by the NHS Executive R\&D. The views expressed herein do not necessarily reflect those of the funding body. Competing interests: NI, CEC, RG, and KW are organisers of the PD MED trial, which is funded by the NHS health technology assessment programme. CEC has received payments from the manufacturers of several of the drugs discussed for consultancy, lecture fees, and travel.

Ethical approval: Not needed.

1 Heikkila RE, Manzino L, Cabbat FC, Duvoisin RC. Protection against the dopaminergic neurotoxicity of 1-methyl-4-phenyl-1,2,3,6-tetrahydropyridine by monoamine oxidase inhibitors. Nature 1984;311:467-9

2 Parkinson Study Group. DATATOP: a multicenter controlled clinical trial in early Parkinson's disease. Arch Neurol 1989;46:1052-60.

3 Lang AE, Lees AJ. MAO-B inhibitors for the treatment of Parkinson's disease. Mov Disord 2002;17(suppl 4):S38-44.

\section{What is already known on this topic}

Selegiline is used either alone or in addition to levodopa to try to slow the progression of Parkinson's disease

One trial reported increased mortality in patients treated with selegiline

\section{What this study adds}

Monoamine oxidase type B inhibitors reduce disability, the need for levodopa, and the incidence of motor fluctuations without substantial side effects or increased mortality

Further large, long term trials comparing selegiline with other available drugs, and assessing patient rated quality of life measures, are needed
4 Lees AJ on behalf of the Parkinson's Disease Research Group of the United Kingdom. Comparison of therapeutic effects and mortality data of levodopa and levodopa combined with selegiline in patients with early, mild Parkinson's disease. BMJ 1995;311:1602-7.

5 Olanow CW, Myllyla VV, Sotaniemi KA, Larsen JP, Palhagen S, Przuntek H, et al. Effect of selegiline on mortality in patients with Parkinson's disease: a meta-analysis. Neurology 1998;51:825-30.

6 Counsell C. Effect of adding selegiline to levodopa in early, mild Parkinson's disease: formal systematic review of data on patients in all relevant trials is required. BMJ 1998;317:1586.

7 Dickersin K, Scherer R, Lefebvre C. Identifying relevant studies for systematic reviews. BMJ 1994;309:1286-91.

8 Early Breast Cancer Trialists' Collaborative Group. Treatment of early breast cancer. Vol 1 : Worldwide evidence 1985-1990. Oxford: Oxford University Press, 1990.

9 Mantel N, Haenszel W. Statistical aspects of the analysis of data from retrospective studies of disease. J Natl Cancer Inst 1959;22:719-48.

10 Peto R, Pike MC, Armitage P, Breslow NE, Cox DR, Howard SV, et al. Design and analysis of randomized clinical trials requiring prolonged observation of each patient: II. analysis and examples. Br J Cancer 1977;35:1-39.

11 Early Breast Cancer Trialists' Collaborative Group. Systemic treatment of early breast cancer by hormonal, cytotoxic, or immune therapy: 133 randomised trials involving 31,000 recurrences and 24,000 deaths among 75,000 women. Lancet 1992:339:1$15,71-85$.

12 Parmar M, Torri V, Stewart L. Extracting summary statistics to perform meta-analyses of the published literature for survival endpoints. Stat Med 1998;17:2815-34.

13 Fleiss JL. The statistical basis of meta-analysis. Stat Methods Med Res 1993;2:121-45.

14 Teravainen H. Selegiline in Parkinson's disease. Acta Neurol Scand 1990;81:333-6.

15 Mally J. Kovacs AB, Stone TW. Delayed development of symptomatic improvement by (-) deprenyl in Parkinson's disease. J Neurol Sci 1995;134:143-5.

16 Parkinson Study Group. A controlled trial of lazabemide (Ro19-6327) in untreated Parkinson's disease. Ann Neurol 1993;33:350-6.

17 Parkinson Study Group. A controlled trial of lazabemide (Ro 19-6327) in levodopa-treated Parkinson's disease. Arch Neurol 1994;51:342-7.

18 Nappi G, Martignoni E, Horowski R, Pacchetti C, Rainer E, Bruggi P, et al. Lisuride plus selegiline in the treatment of early Parkinson's disease. Acta Neurol Scand 1991;83:40710.

19 Allain H, Pollak P, Neukirch HC. Symptomatic effect of selegiline in de novo Parkinsonian patients: the French selegiline multicenter trial. Mov Disord 1993;8(suppl 1):S3640.

20 Parkinson Study Group. A controlled trial of rasagiline in early Parkinson disease: the TEMPO study. Arch Neurol 2002;59:1937-43.

21 Palhagen S, Heinonen EH, Hagglund J, Kaugesaar T, Kontants H, Maki-Ikola O, et al Selegiline delays the onset of disability in de novo Parkinsonian patients. Neurology 1998;51:520-5. 
22 Kirollos C, Charlett A, Bowes SG, Purkiss AG, O'Neill CJA, Weller C, et al. Time course of physical and psychological responses to selegiline monotherapy in newly diagnosed, idiopathic parkinsonism. Eur J Clin Pharmacol 1996;50:7-18.

23 Parkinson Study Group. Effect of lazabemide on the progression of disability in early Parkinson's disease. Ann Neurol 1996;40:99-107.

24 Olanow CW, Hauser RA, Gauger L, Malapira T, Koller W, Hubble J, et al. The effect of deprenyl and levodopa on the progression of Parkinson's disease. Ann Neurol 1995;38:771-7.

25 Caraceni T, Musicco M. Levodopa or dopamine agonists, or deprenyl as initia treatment for Parkinson's disease: a randomized multicenter study. Parkinsonism Relat Disord 2001;7:107-14.

26 Tetrud JW, Langston JW. The effect of deprenyl (selegiline) on the natural history of Parkinson's disease. Science 1989;245:519-22.

27 Larsen JP, Boas J, Erdal JE for the Norwegian-Danish Study Group.. Does selegiline modify the progression of early Parkinson's disease? Results from a five-year study. Eur J Neurol 1999;6:539-47.

28 Przuntek H, Conrad B, Dichgans J, Kraus PH, Krauseneck P, Pergande G, et al SELEDO: a 5-year long-term trial on the effect of selegiline in early parkinsonian patients treated with levodopa. Eur J Neurol 1999;6:141-50.

29 Myllyla VV, Sotaniemi KA, Vuorinen JA, Heinonen EH. Selegiline as initial treatment in de novo parkinsonian patients. Neurology 1992;42:339-43.

30 Myllyla VV, Heinonen EH, Vuorinen JA, Kilkku OI, Sotaniemi KA. Early selegiline therapy reduces levodopa dose requirement in Parkinson's disease. Acta Neurol Scand 1995;91:177-82.

31 Myllyla VV, Sotaniemi KA, Hakulinen P, Maki-Ikola O, Heinonen EH. Selegiline as the primary treatment of Parkinson's disease: a long-term double-blind study. Acta Neurol Scand 1997:95:211-8.

32 Parkinson Study Group. Effects of deprenyl on the progression of disability in early Parkinson's disease. N Engl J Med 1989;321:1364-71.

33 Parkinson Study Group. Effects of tocopherol and deprenyl on the progression of disability in early Parkinson's disease. N Engl J Med 1993;328:176-83.

34 Parkinson Study Group. Mortality in DATATOP: a multicenter trial in early Parkinson's disease. Ann Neurol 1998;43:318-25.

35 Lees AJ, Katzenschlager R, Head J, Ben-Shlomo Y on behalf of the Parkinson's Disease Research Group of the United Kingdom. Ten-year follow-up of three different initil treatments in de-novo PD: a randomized trial. Neurology 2001:57:1687-94.
36 Ben-Shlomo Y, Churchyard A, Head J, Hurwitz B, Overstall P, Ockelford J, et al. Invesigation by Parkinson's Disease Research Group of United Kingdom into excess mortality seen with combined levodopa and selegiline treatment in patients with early, mild Parkinson's disease: further results of randomised trial and confidential inquiry. BMJ 1998;316:1191-6.

37 Ives NJ, Stowe RL, Shah L, Hawker RJ, Clarke CE, Gray RG, et al. Meta-analysis of 5038 patients in 28 randomised trials comparing dopamine agonists with levodopa. Alzheimer's and Parkinson's diseases: new perspectives. 6th International Conference AD/PD, Seville, Spain, May 8-12 2003. Book of abstracts:119.

38 Jenkinson C, Fitzpatrick R, Peto V. The Parkinson's disease questionnaire: user manual for the PDQ-39, PDQ-8 and PDQ summary index. Oxford: Health Services Research Unit, University of Oxford, 1998.

(Accepted 6July 2004)

doi 10.1136/bmj.38184.606169.AE

Birmingham Clinical Trials Unit, University of Birmingham, Birmingham B15 2RR

Natalie J Ives statistician

Rebecca L Stowe information scientist

Joanna Marro research assistant

Richard Gray professor of medical statistics

Keith Wheatley professor of medical statistics

Department of Neurology, Aberdeen Royal Infirmary, Aberdeen AB25 2ZN Carl Counsell consultant neurologist

Medicine and Therapeutics, University of Aberdeen, Aberdeen AB25 2ZN Angus Macleod medical student

Department of Neurology, City Hospital NHS Trust, Birmingham B18 7QH Carl E Clarke consultant neurologist

Correspondence to: Natalie Ives n.j.ives@bham.ac.uk 